\title{
Adsorption of Atenolol on Kaolinite
}

\author{
Yingmo Hu, ${ }^{1}$ Nicole M. Fitzgerald, ${ }^{2}$ Guocheng Lv, ${ }^{1}$ Xuebing Xing, \\ Wei-Teh Jiang, ${ }^{3}$ and Zhaohui $\mathrm{Li}^{2}$
}

${ }^{1}$ Beijing Key Laboratory of Materials Utilization of Nonmetallic Minerals and Solid Wastes, National Laboratory of Mineral Materials, School of Materials Science and Technology, China University of Geosciences, Beijing, 29 Xueyuan Road, Beijing 100083, China

${ }^{2}$ Geosciences Department, University of Wisconsin-Parkside, Kenosha, WI 53144, USA

${ }^{3}$ Department of Earth Science, National Cheng Kung University, Tainan 70101, Taiwan

Correspondence should be addressed to Zhaohui Li; li@uwp.edu

Received 25 August 2014; Revised 12 December 2014; Accepted 13 December 2014

Academic Editor: Hanlie Hong

Copyright (C) 2015 Yingmo Hu et al. This is an open access article distributed under the Creative Commons Attribution License, which permits unrestricted use, distribution, and reproduction in any medium, provided the original work is properly cited.

In this study the adsorption of atenolol (AT), a $\beta$-blocker, on kaolinite, a clay mineral of low surface charge, was investigated under varying initial AT concentration, equilibrium time, solution $\mathrm{pH}$, ionic strength, and temperature conditions. The results showed that the amounts of AT uptake by kaolinite were close to its cation exchange capacity value and the AT adsorption was almost instantaneous, suggesting a surface adsorption. The adsorption was exothermic and the free energy of adsorption was small negative, indicating physical adsorption. The increase in ionic strength of the solution drastically reduced AT uptake on kaolinite. A significant reduction in AT uptake was found at solution $\mathrm{pH}$ below 5 or above 10. The FTIR results showed band shifting and disappearance for NH bending vibration and benzene ring skeletal vibration at 3360 and $1515 \mathrm{~cm}^{-1}$ and band splitting at 1412 and $1240 \mathrm{~cm}^{-1}$ attributed to $\mathrm{C}-\mathrm{N}$ valence vibration coupled with $\mathrm{NH}$ bending vibrations and alkyl aryl ether linkage, suggesting the participation of $\mathrm{NH},-\mathrm{O}-$, and benzene ring for AT adsorption on kaolinite.

\section{Introduction}

Due to their widespread use and limited human metabolism $\beta$-blockers are widely detected in sewage effluents and surface waters [1]. In Phase I study of the risk assessment, the initial predicted environmental concentration of atenolol (AT), one of the commonly prescribed $\beta$-blockers, in surface water, was $500 \mathrm{ng} / \mathrm{L}$, far exceeding the action limit of $10 \mathrm{ng} / \mathrm{L}$ [1]. Atenolol showed low potential for bioaccumulation as indicated by its low lipophilicity $\left(\log K_{\mathrm{OW}}=0.16\right)$ and low affinity for sorption to the sediment [1]. However, transport of AT in sandy aquifer materials was strongly retarded despite its hydrophilic character [2]. The experimentally determined AT distribution coefficient ( $K_{d}$ value) was much higher in comparison to the other neutral compounds or carboxylic acids [3].

Common earth materials include clay minerals and zeolite, owing to their larger specific surface area (SSA) and inexpensive material costs, were studied extensively for drug uptake and release. Montmorillonite (MMT) was tested as a carrier for sustainable release of AT over a period of 24 hours in simulated gastric and intestinal fluids [4]. Extended release of AT was also tested using a multifunctional system of [SBA$15 / \mathrm{Fe}_{3} \mathrm{O}_{4} / \mathrm{P}(N$-iPAAm $\left.)\right]$ hybrids of interest for bioapplications [5]. Sorption of AT on fine ceramic pseudoboehmite resulted in no loss in its chemical stability [6]. Attapulgites modified by different reagents including hydrochloric acid, silane coupling agent, and chitosan showed extensive uptake of propranolol, another $\beta$-blocker medicine [7]. Adsorption of AT on a kaolinite, a bentonite, and a zeolite reached 20, 20, and $40 \mathrm{mmol} / \mathrm{kg}$, respectively, while modification of the kaolinite and bentonite with an organic cation octadecyltrimethylammonium resulted in minimal influence on AT adsorption capacity but reduced affinity [8].

In addition to common Earth materials, removal of AT by activated carbon $(\mathrm{AC})$ or granular activated carbon (GAC) was also conducted $[9,10]$. Column experiments showed that AT breakthrough time decreased as its input concentration and flow rate increased and column length decreased $[10,11]$. The amounts of AT uptake on AC or GAC were as high as $750 \mathrm{mmol} / \mathrm{kg}[10]$. 
Even with this progress, conflict results were reported on interactions between AT and Earth materials. The strongest retardation and therefore the highest $\log K_{\mathrm{OC}}$ values were observed for the cationic compounds AT, diazepam, and trimethoprim [2]. On the contrary, AT showed a low affinity for the sediment and a rather low $\mathrm{DT}_{50}$ (dissipation time at which $50 \%$ of the substance is removed) of $3 \mathrm{~d}$ for the water compartment [1]. A similar low affinity for stream sediment was also found [12].

In addition to adsorption, degradation of $\beta$-blockers was also experienced in extensive study, though with conflict results. One study found that AT was not readily ultimately biodegradable [1]. In another study, elevated biodegradability in the surface water-sediment systems with $90 \%$ disappearance $\left(\mathrm{DT}_{90}\right)$ for AT was observed in 10 days [12]. Abiotic processes, most likely sorption of the positively charged AT to clay minerals, dominated the first 5-10 d of the AT removal experiment under nitrate reducing conditions, yielding removal of about $14 \%$ [13]. In the presence of hydroxyl radical six atenolol decomposition products at detectable levels were revealed by LC-MS at multiple irradiation doses; however, the fraction of hydroxyl radical available to degrade the atenolol was only $0.19 \%$ [14]. Under 240 min UVA irradiation in the absence of catalyst, the extent of photolytic conversion of AT was only $12 \%$, but the conversion increased to $85 \%$ in the presence of $\mathrm{TiO}_{2}$ as the photocatalyst [15]. In addition, the data on AT removal were very inconsistent and the removal rates varied from less than $10 \%$ up to $95 \%$ depending on the treatment [16].

As the presence of solid would strongly affect the distribution of pharmaceutical compounds between the solid and liquid phases, which would ultimately affect the performance of their biotic or abiotic degradation, it is necessary to assess the degrees of uptake of pharmaceutical compounds on solid under different physic-chemical conditions. Because of the lack of ecotoxicological data, low metabolism, wide use, and frequent detection in sewage effluents and receiving waters [1], AT was chosen in this study for its interactions with low charge clay minerals, using kaolinite as an example.

\section{Materials and Methods}

The material used was KGa-2, a poorly crystalized kaolinite obtained from the Clay Mineral Repository in Purdue University. It had a cation exchange capacity (CEC) value of $37 \mathrm{mmol} / \mathrm{kg}$ [17], with $\mathrm{Na}^{+}, \mathrm{Ca}^{2+}$, and $\mathrm{Mg}^{2+}$ as the major exchangeable cations. It has an SSA of $21.7 \mathrm{~m}^{2} / \mathrm{g}$ [18]. It was used without further pretreatment.

The atenolol (CAS number: 29122-68-7) with a purity of $>98 \%$ was purchased from Tokyo Chemical Industry Co., Ltd. (Figure 1). It has a formula mass of $266.336 \mathrm{~g} / \mathrm{mol}$ and a $\mathrm{p} K_{a}$ value of $9.6[1,19-21]$. Its solubility in pure water was $9.34 \mathrm{~g} / \mathrm{L}$ [22]. An experimental and predicted solubility of $\log S_{0}=$ -1.3 and -1.94 , corresponding to 13 and $3 \mathrm{~g} / \mathrm{L}$, was also reported $[23,24]$. At $37^{\circ} \mathrm{C}$ its solubility increased to $37 \mathrm{~g} / \mathrm{L}$ [15]. A $\log K_{\mathrm{OW}}$ value of $0.1[1,13]$ and a $K_{d}$ of $44 \mathrm{~L} / \mathrm{kg}$ for sludge [1] were also reported. Stable concentrations of AT were observed in the control samples with Milli-Q water [3].

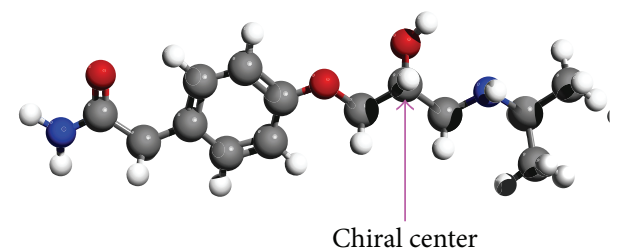

Figure 1: Molecular structure of atenolol. It could be a racemic mixture and the chiral center is at the $\mathrm{C}$ marked with an arrow. The red is $\mathrm{O}$, the blue is $\mathrm{N}$, and the dark gray is $\mathrm{C}$, while the white is $\mathrm{H}$.

For the AT adsorption isotherm study, $1.0 \mathrm{~g}$ of kaolinite and $10 \mathrm{~mL}$ of AT at concentrations of $0.0,0.6,1.2,1.8,2.4,3.0$, 3.6 , and $4.0 \mathrm{mmol} / \mathrm{L}$ were combined in $50 \mathrm{~mL}$ centrifuge tubes. For all other studies, the initial AT concentration was fixed at 2.0 or $4.0 \mathrm{mmol} / \mathrm{L}$. For AT adsorption kinetics, the equilibrium time was $0.25,0.5,1,2,4,8,16$, and $24 \mathrm{~h}$. The equilibrium solution $\mathrm{pH}$ was maintained at 2-11 with an increment of 1 for the $\mathrm{pH}$-dependent study, while the ionic strength was adjusted to reach $\mathrm{NaCl}$ concentrations of 0.001 , $0.01,0.1$, and $1.0 \mathrm{M}$. The temperature study was conducted at 22,32 , and $42^{\circ} \mathrm{C}$. The mixtures were shaken at $150 \mathrm{rpm}$ for $24 \mathrm{~h}$, except the kinetic study, and were then centrifuged at $3500 \mathrm{rpm}$ for $10 \mathrm{~min}$, and the supernatants passed through $0.45 \mu \mathrm{m}$ syringe filters before being analyzed for the equilibrium AT concentrations using an UV-Vis method.

The AT concentration was measured by an UV-Vis

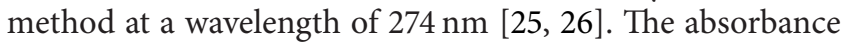
value at this wavelength was stable at $\mathrm{pH} 1-11$ ranges [4]. In this study, the absorbance was determined at a wavelength of $236 \mathrm{~nm}$. At this wavelength, the absorbance value was also $\mathrm{pH}$-independent at $\mathrm{pH} 1-11$ ranges [4]. Meanwhile, the absorbance value at this wavelength is large, making it more sensitive for AT analyses.

The FTIR analysis was conducted using a Jasco FT/IR4100 spectrometer equipped with a ZnSe crystal and attenuated total reflection (ATR) accessory. The spectra were obtained from 600 to $4000 \mathrm{~cm}^{-1}$ by accumulating 256 scans at a resolution $4 \mathrm{~cm}^{-1}$. Powder XRD analyses of AT-adsorbed kaolinite were carried out with $\mathrm{CuK} \alpha$ radiation at $40 \mathrm{kV}$ and $40 \mathrm{~mA}$ on a D8 ADVANCE diffractometer (Bruker Corp.). Unoriented samples were scanned from 2 to $22^{\circ} 2 \theta$ with a scanning speed of $0.01^{\circ} / \mathrm{s}$. The desorption of exchangeable cations was determined using an ion chromatography (IC).

Molecular simulation was performed using the module Forcite of Materials Studio 6.0 software to investigate the sorption sites of AT on kaolinite. The kaolinite model was constructed and the atomic coordinates were derived from the space group of $\mathrm{C} 1$ with $a=5.15 \AA, b=8.93 \AA, c=$

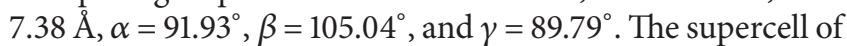
the model was made of 12 kaolinite unit cells at $3 a \times 2 b \times 2 c$. The established model was optimized geometrically. The temperature was set at $298 \mathrm{~K}$ and time was $1 \mathrm{~ns}$ with a time step of $1 \mathrm{fs}$. Universal force field was used during the simulation. The Ewald summation method was used to calculate the electrostatic interaction. After the system reached equilibrium at about $500 \mathrm{ps}$, the NVT kinetic simulation was 


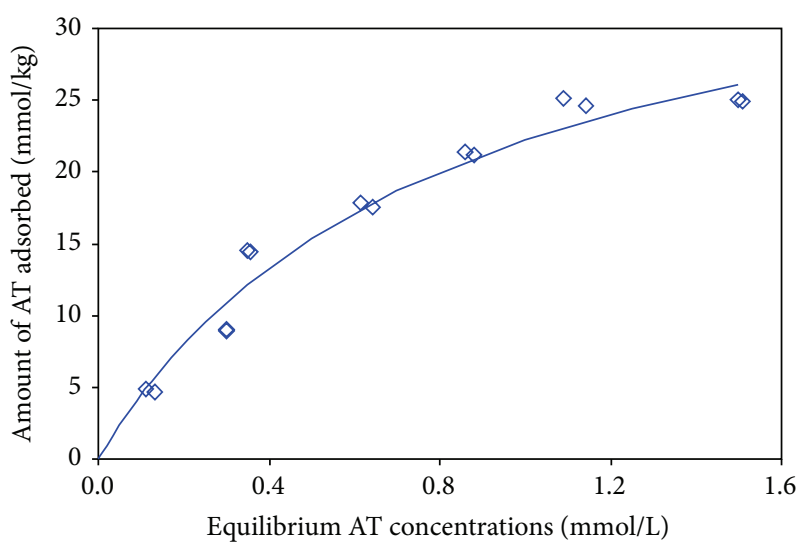

FIgURE 2: Adsorption of atenolol on kaolinite. The line is the Langmuir fit to the observed data.

performed under the same time constant and temperature conditions. The data were collected at the last $500 \mathrm{ps}$ for later analyses.

\section{Results and Discussion}

3.1. AT Adsorption Isotherm. Adsorption of AT on kaolinite followed the Langmuir adsorption isotherm (Figure 2):

$$
C_{S}=\frac{K_{L} S_{m} C_{L}}{1+K_{L} C_{L}}
$$

where $C_{S}$ is the amount of AT adsorbed at equilibrium $(\mathrm{mmol} / \mathrm{kg}), S_{m}$ the apparent sorption capacity $(\mathrm{mmol} / \mathrm{kg})$, $C_{L}$ the equilibrium AT concentration $(\mathrm{mmol} / \mathrm{L})$, and $K_{L}$ the Langmuir coefficient $(\mathrm{L} / \mathrm{mmol})$. Equation (1) can be rearranged to a linear form:

$$
\frac{C_{L}}{C_{S}}=\frac{1}{K_{L} S_{m}}+\frac{C_{L}}{S_{m}}
$$

so that $K_{L}$ and $S_{m}$ can be determined by linear regression. The adsorption capacity of AT on kaolinite was $40 \mathrm{mmol} / \mathrm{kg}$ and the $K_{L}$ was $1.25 \mathrm{~L} / \mathrm{mmol}$. The values are comparable to AT adsorption at 20,20 , and $40 \mathrm{mmol} / \mathrm{kg}$ on kaolinite, bentonite, and zeolite, respectively [8].

The equilibrium uptake of AT on an MMT also followed the Langmuir model with an AT adsorption capacity of $86 \mathrm{mg} / \mathrm{g}$ or $320 \mathrm{mmol} / \mathrm{kg}$ [4]. Multilayer adsorption of AT on natural kaolin was indicated by slight increase of AT adsorption values in the last part of the isotherm [8]. A linear adsorption of AT on some river sediments or silt loam soil was reported with $K_{d}$ values ranging from 1.3 for the river sediments to $110 \mathrm{~L} / \mathrm{kg}$ for the silt loam soil due to its higher CEC value [3]. Adsorption of AT on GAC reached a capacity of $750 \mathrm{mmol} / \mathrm{kg}$ in comparison to the measured basicity of $802 \mathrm{mmol}_{\mathrm{c}} / \mathrm{kg}[10]$.

3.2. AT Adsorption Kinetics. AT adsorption on kaolinite was very fast, especially when the initial AT concentration was low (Figure 3). The equilibrium could be reached in less than

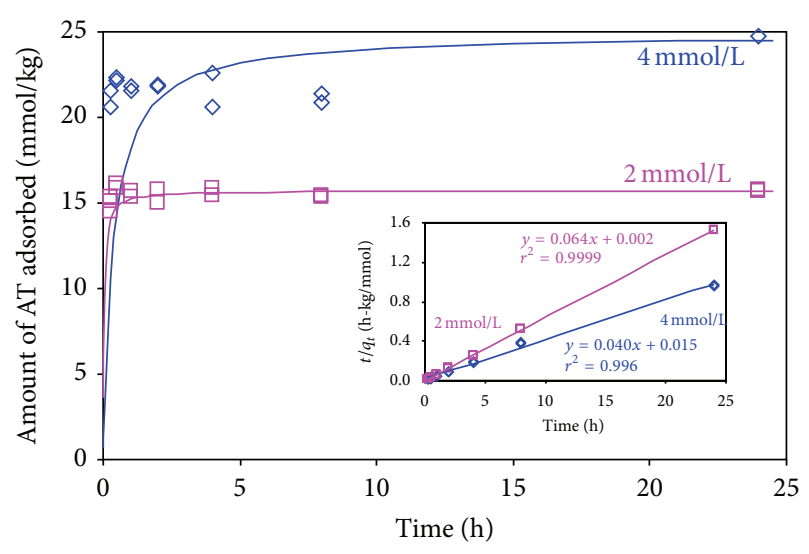

FIGURE 3: Kinetics of AT adsorption on kaolinite from initial concentrations of 2 and $4 \mathrm{mmol} / \mathrm{L}$. The lines are pseudo-secondorder fits to the observed data. Inset is the plot based on (4).

half an hour. This quick sorption may indicate a surface process; thus diffusion may not play a significant role. The data of AT adsorption were fitted to several kinetic models and the pseudo-second-order model fitted the experimental data well [27]:

$$
q_{t}=\frac{k q_{e}^{2} t}{1+k q_{e} t}
$$

where $q_{e}$ and $q_{t}$ are amounts of AT adsorbed at equilibrium and at time $t(\mathrm{mmol} / \mathrm{kg})$ and $k$ is the pseudo-second-order rate constant ( $\mathrm{kg} / \mathrm{mmol}-\mathrm{h})$. Equation (3) can be rearranged to a linear form

$$
\frac{t}{q_{t}}=\frac{1}{k q_{e}^{2}}+\frac{1}{q_{e}} t
$$

so that $k$ and $q_{e}$ can be determined by linear regression. The rate constants thus obtained were 0.1 and $1.9 \mathrm{~kg} / \mathrm{mmol}-\mathrm{h}$, and the initial rates were 68 and $476 \mathrm{mmol} / \mathrm{kg}$-h, for AT adsorption on kaolinite from initial concentrations of 4 and $2 \mathrm{mmol} / \mathrm{L}$.

A rate constant of $0.082 \mathrm{~g} / \mathrm{mg}$-min or $1.2 \mathrm{~kg} / \mathrm{mmol}$-h was reported for AT adsorption on MMT [4]. The $q_{e}$ values were 25 and $16 \mathrm{mmol} / \mathrm{kg}$, agreeing well with the isotherm study. Sorption of AT on AC reached equilibrium in less than $2 \mathrm{~h}$ [9] or less than $8 \mathrm{~h}$ [10]. The quick AT adsorption on kaolinite confirmed that surface adsorption is the dominant process and diffusion may not play a significant role.

3.3. Solution Ionic Strength Effect. The amount of AT adsorbed decreased from $16 \mathrm{mmol} / \mathrm{kg}$ at very low ionic strength to almost zero at a background $\mathrm{NaCl}$ concentration of $1 \mathrm{~mol} / \mathrm{L}$ (Figure 4 ). In addition, the free energy of adsorption $\Delta G$ can be calculated from the $K_{d}=C_{S} / C_{L}$ by

$$
\Delta G=-R T \ln K_{d},
$$

where $R$ is the gas constant and $T$ is the reaction temperature in $K$. A systematic increase in $\Delta G$ was found as the solution 


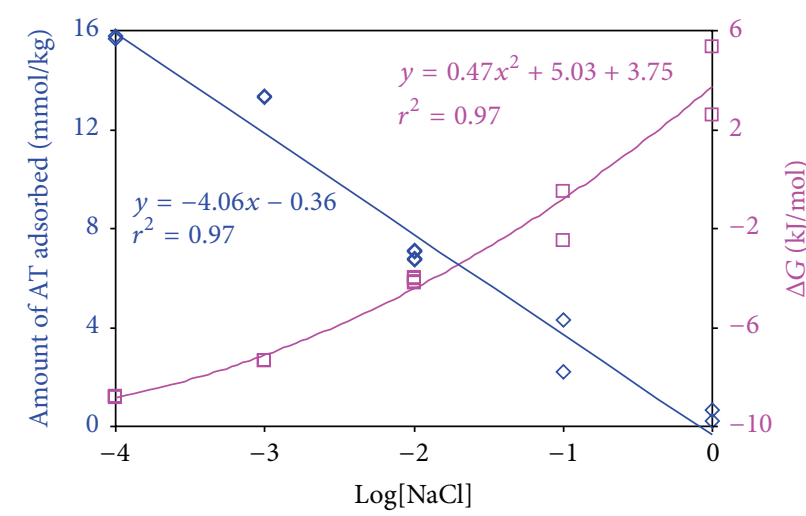

FIGURE 4: Influence of solution ionic strength on AT adsorption on kaolinite from $2 \mathrm{mmol} / \mathrm{L}$ solution and changes in free energies associated with AT adsorption.

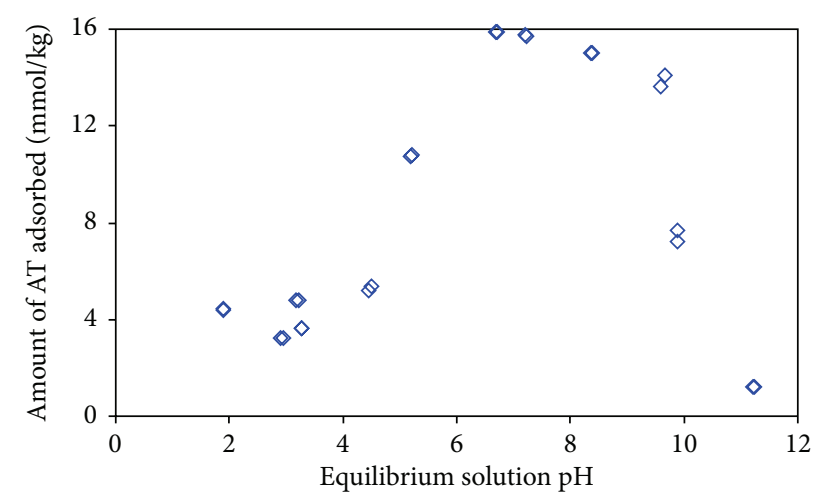

FIGURE 5: AT adsorption on kaolinite as affected by equilibrium solution $\mathrm{pH}$.

ionic strength increases, reflecting strong completing effect of background salt $\mathrm{NaCl}$ against $\mathrm{AT}$ adsorption. Previous results showed that, with the increase of $\mathrm{Na}^{+}$, more and more sorbed propranolol molecules desorbed into the aqueous phase [7].

3.4. $p H$ Effect. Solution $\mathrm{pH}$ had a significant effect on AT uptake by kaolinite (Figure 5). When solution $\mathrm{pH}$ was below 5 or above 10, the uptake of AT on kaolinite was drastically reduced (Figure 5). Similarly, aqueous phase $\mathrm{pH}$ showed significant influence on AT adsorption onto AC with the highest AT adsorption at $\mathrm{pH} 7$ [9]. The solubility of AT was higher than $1 \mathrm{~mol} / \mathrm{L}$ when solution $\mathrm{pH}$ was below 7 and increased with decreasing solution $\mathrm{pH}$ [23]. Even at $\mathrm{pH} 11$, the solubility of AT was still much greater than the initial concentration of $2 \mathrm{mmol} / \mathrm{L}$ [23]. Thus, precipitation would not be a factor for the reduced AT adsorption under low and high $\mathrm{pH}$ conditions. The decreased AT uptake under low solution $\mathrm{pH}$ conditions could be attributed to competition between $\mathrm{H}^{+}$ and $\mathrm{ATH}^{+}$for sorption sites. Meanwhile, as the solution $\mathrm{pH}$ was higher than the $\mathrm{p} K_{a}$ of AT, the significant reduction in AT uptake could be attributed to the loss of electrostatic interactions between neutral AT molecule and negatively charged kaolinite surfaces. In contrast, relatively stable adsorption of propranolol on attapulgites or modified attapulgites was

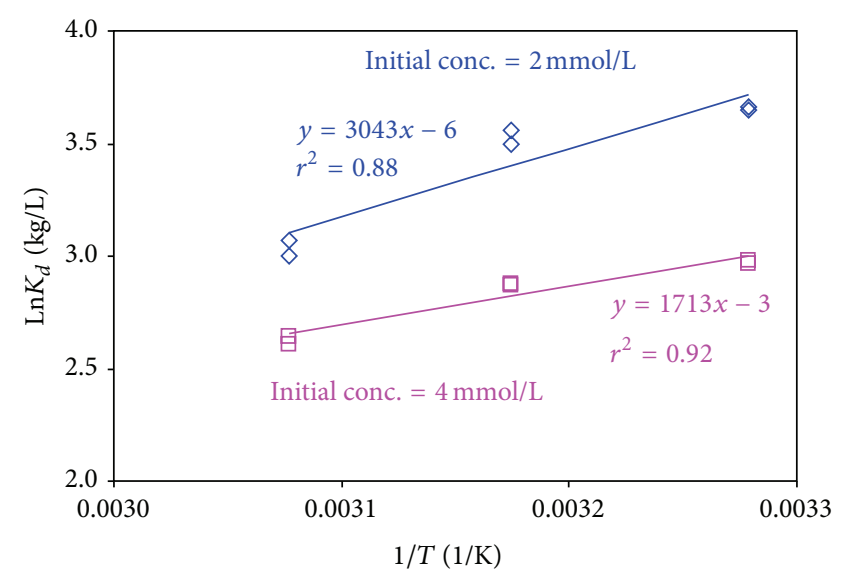

FIGURE 6: Change in distribution coefficient as affected by temperature for AT adsorption on kaolinite.

TABLE 1: Thermodynamic parameters of AT adsorption on kaolinite.

\begin{tabular}{|c|c|c|c|c|c|}
\hline \multirow{2}{*}{$T(\mathrm{~K})$} & \multicolumn{3}{|c|}{$\Delta G^{\circ}(\mathrm{kJ} / \mathrm{mol})$} & \multirow{2}{*}{$\Delta H^{\circ}(\mathrm{kJ} / \mathrm{mol})$} & \multirow{2}{*}{$\Delta S^{\circ}(\mathrm{kJ} / \mathrm{mol}-\mathrm{K})$} \\
\hline & 305 & 315 & 325 & & \\
\hline $2 \mathrm{mmol} / \mathrm{L}$ & -9.4 & -8.9 & -8.4 & -25.3 & -0.05 \\
\hline $4 \mathrm{mmol} / \mathrm{L}$ & -7.6 & -7.4 & -7.2 & -14.2 & -0.02 \\
\hline
\end{tabular}

found in initial $\mathrm{pH} 3-11$ range [7]. The AT retardation factor $R$ in a sandy aquifer material decreased from 23.3 to 15.8 as the $\mathrm{pH}$ increased from 4 to 8 [2].

3.5. Temperature Effect. As the temperature increased, the $K_{d}$ decreased, reflecting a slightly exothermic reaction for AT adsorption on kaolinite (Figure 6). Also, the changes in enthalpy after AT adsorption from 2 to $4 \mathrm{mmol} / \mathrm{L}$ solution were -25 and $-14 \mathrm{~kJ} / \mathrm{mol}$, confirming the exothermic reaction. Moreover, the $\Delta G$ values were in the range from -7 to $-9 \mathrm{~kJ} / \mathrm{mol}$ (Table 1), much less than the changes affected by solution ionic strength. In comparison, adsorption of AT on AC showed endothermic feature, too, with $\Delta G, \Delta H$, and $\Delta S$ values of $-2--5 \mathrm{~kJ} / \mathrm{mol}, 29 \mathrm{~kJ} / \mathrm{mol}$, and $0.09 \mathrm{~kJ} / \mathrm{mol} / \mathrm{K}$, respectively [9]. The lower negative values of $\Delta G$ for AT adsorption on kaolinite may indicate physical adsorption such as cation exchange processes as observed in the case of ciprofloxacin adsorption on the same kaolinite [28].

3.6. FTIR Analysis. The FTIR spectra of kaolinite adsorbed with different amounts of AT displayed both bands of raw kaolinite and AT (Figure 7(a)). Their characteristic band locations and assignments were listed in Table 2. The IR spectrum of the pure AT displayed characteristic peaks at $3362 \mathrm{~cm}^{-1}, 3172 \mathrm{~cm}^{-1}$, and $1636 \mathrm{~cm}^{-1}$ due to $\mathrm{O}-\mathrm{H}, \mathrm{N}-\mathrm{H}$, and $\mathrm{C}=\mathrm{O}$ groups, respectively $[6,29,30]$. Other bands observed were at $1245,1510,1184,805$, and $820 \mathrm{~cm}^{-1}$ [6]. For pure AT the strong band at $1638 \mathrm{~cm}^{-1}$, originating from $\mathrm{C}=\mathrm{O}$ valence vibrations (amide band I), decreased significantly and shifted to $1668 \mathrm{~cm}^{-1}$, after inclusion into the cavity of 2-hydroxypropyl- $\beta$-cyclodextrin owing to the restriction of this vibration [29]. After the interaction with pseudoboehmite it 


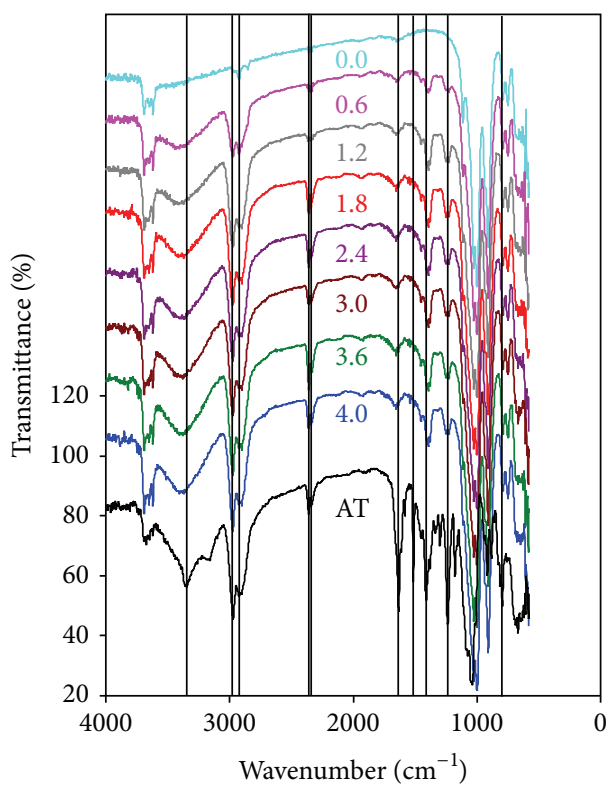

(a)

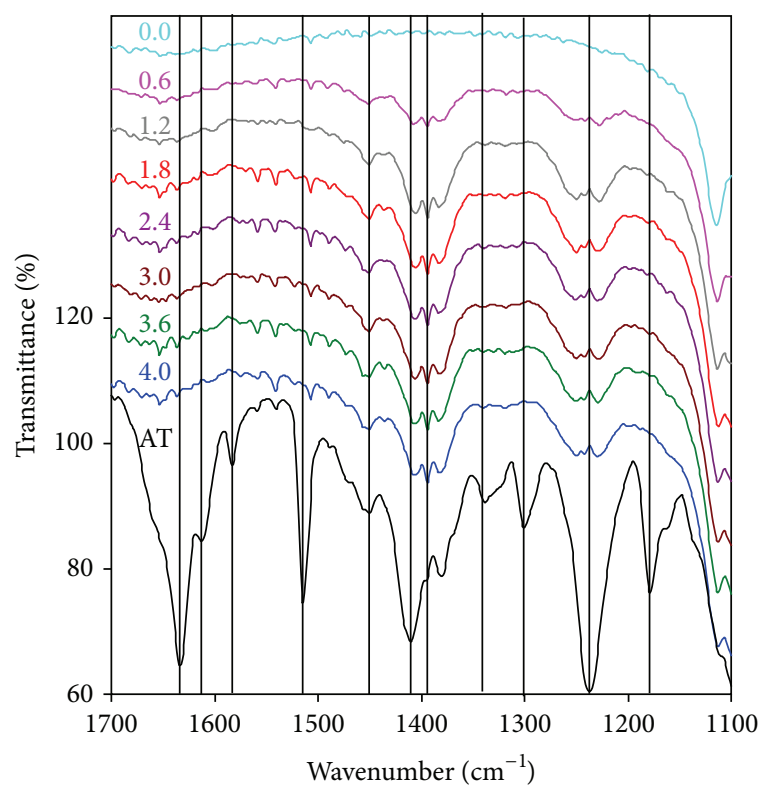

(b)

FIGURE 7: FTIR spectra of crystalline AT, and kaolinite with different amounts of AT adsorption in the ranges of $600-4000 \mathrm{~cm}^{-1}(\mathrm{a})$ and $1100-1700 \mathrm{~cm}^{-1}$ (b). The values indicate initial AT concentrations in $\mathrm{mmol} / \mathrm{L}$.

TABLE 2: FTIR bands for AT and AT adsorbed on KGa-2.

\begin{tabular}{|c|c|c|c|c|c|c|c|c|c|}
\hline $0.0 \mathrm{mmol} / \mathrm{L}$ & $0.6 \mathrm{mmol} / \mathrm{L}$ & $1.2 \mathrm{mmol} / \mathrm{L}$ & $1.8 \mathrm{mmol} / \mathrm{L}$ & $2.4 \mathrm{mmol} / \mathrm{L}$ & $3.0 \mathrm{mmol} / \mathrm{L}$ & $3.6 \mathrm{mmol} / \mathrm{L}$ & $4.0 \mathrm{mmol} / \mathrm{L}$ & Pure AT & Band assignments \\
\hline & & & & & & & & 3700 & \\
\hline- & 3410 & 3410 & 3410 & 3410 & 3410 & 3410 & 3410 & 3360 & NH banding vibration ${ }^{1}$ \\
\hline \multirow[t]{2}{*}{-} & - & - & - & - & - & - & - & 3158 & $\mathrm{NH}_{\text {valence vibrations }}^{2}$ \\
\hline & 2972 & 2972 & 2972 & 2972 & 2972 & 2972 & 2972 & 2972 & $\mathrm{C}-\mathrm{H}$ stretching ${ }^{1}$ \\
\hline 2923 & 2923 & 2923 & 2923 & 2923 & 2923 & 2923 & 2923 & 2923 & \\
\hline 2902 & 2902 & 2902 & 2902 & 2902 & 2902 & 2902 & 2902 & 2901 & \\
\hline 2359 & 2359 & 2359 & 2359 & 2359 & 2359 & 2359 & 2359 & 2359 & \\
\hline \multirow[t]{2}{*}{1654} & 1654 & 1654 & 1654 & 1654 & 1654 & 1654 & 1654 & 1633 & $\mathrm{C}=\mathrm{O}^{1,2}$ \\
\hline & & & & & & & & 1515 & $\begin{array}{l}\text { benzene ring skeletal } \\
\text { vibration }{ }^{1} \text { or } \mathrm{C}=\mathrm{C} \text { valence } \\
\text { vibrations of the aromatic }\end{array}$ \\
\hline 1395,1408 & 1395,1408 & 1395,1408 & 1395,1408 & 1395,1408 & 1395,1408 & 1395,1408 & 1395,1408 & 1410 & $\mathrm{NH}$ bending vibrations ${ }^{2}$ \\
\hline 1385 & 1385 & 1385 & 1385 & 1385 & 1385 & 1385 & 1385 & 1381 & \\
\hline- & - & - & - & - & - & - & - & 1338 & \\
\hline - & - & - & - & - & - & - & - & 1301 & \\
\hline 1252,1230 & 1252,1230 & 1252,1230 & 1252,1230 & 1252,1230 & 1252,1230 & 1252,1230 & 1252,1230 & 1237 & Alkyl aryl ether linkage ${ }^{1}$ \\
\hline \multirow[t]{7}{*}{-} & - & - & - & - & - & - & - & 1178 & \\
\hline & & & & & & & & 1088 & \\
\hline & & & & & & & & 1054 & \\
\hline & & & & & & & & 917 & \\
\hline & & & & & & & & 911 & \\
\hline & & & & & & & & 795 & \\
\hline & & & & & & & & 669 & \\
\hline
\end{tabular}

\footnotetext{
${ }^{1}$ Seema and Datta [4].

${ }^{2}$ Nikolić et al. [29].
} 
shifted to $1650 \mathrm{~cm}^{-1}$ [6]. In this study, similar observation was found, and the band shifted from 1633 to $1654 \mathrm{~cm}^{-1}$ with a significant decrease in its intensity (Figure 7(b)).

The peak of $2972 \mathrm{~cm}^{-1}$ was due to C-H stretching [4]. It remained in the same location after $\mathrm{AT}$ adsorption on kaolinite (Table 2). A small band at $3350 \mathrm{~cm}^{-1}$ and $1506 \mathrm{~cm}^{-1}$ corresponding to $\mathrm{NH}$ bending vibration and benzene ring skeletal vibration, respectively, from AT also appeared in MMT-AT complex and was attributed to the presence of organic cations AT in the interlayer region of the MMT layers [4]. In this study, the $3350 \mathrm{~cm}^{-1}$ band that occurred at $3360 \mathrm{~cm}^{-1}$ shifted to $3410 \mathrm{~cm}^{-1}$ after adsorption on kaolinite, while the benzene ring skeletal vibration was at $1515 \mathrm{~cm}^{-1}$ and also disappeared after AT adsorption on kaolinite. Similarly, the band at $1515 \mathrm{~cm}^{-1}$ disappeared after forming MMT-AT complex [29].

The peak at $1240 \mathrm{~cm}^{-1}$ was due to alkyl aryl ether linkage [4]. In this study, there is a single sharp peak located at $1237 \mathrm{~cm}^{-1}$ for crystalline AT. However, this peak split into two peaks, located at 1230 and $1252 \mathrm{~cm}^{-1}$, respectively, after being adsorbed onto the surface of kaolinite (Figure $7(b)$ ). The amide band III, originating from the $\mathrm{C}-\mathrm{N}$ valence vibration coupled with $\mathrm{NH}$ bending vibrations, occurred at $1417 \mathrm{~cm}^{-1}$ for crystalline AT but was absent when forming a complex with MMT [29]. Similarly, this band was split into two bands also (Figure $7(\mathrm{~b})$ ). The band at $3180 \mathrm{~cm}^{-1}$ originating from the NH valence vibrations was present in the spectrum of crystalline AT but was absent after being uptaken on MMT [29]. This band occurred at $3158 \mathrm{~cm}^{-1}$ but was absent after being adsorbed on kaolinite (Table 2). New peaks at wavenumbers $2300 \mathrm{~cm}^{-1}$ and $1719 \mathrm{~cm}^{-1}(\mathrm{NC}=\mathrm{N}-, \mathrm{NC}=\mathrm{C}, \mathrm{C}=\mathrm{O}$ stretch) were noticed on $\mathrm{AC}$ after AT adsorption and were attributed to chemical type of adsorption reaction [9]. In this study, these two new peaks were never observed.

3.7. X-Ray Diffraction Analysis. The characteristic peaks of AT are located at $2 \theta$ at $3.2,6.4$, and $9.6^{\circ}$, corresponding to (200), (400), and (600) diffractions [31]. These peaks were present in the mixture of AT and kaolinite at the level of $25 \mathrm{mmol} / \mathrm{kg}$ (Figure 8). However, these peaks were absent after being adsorbed on kaolinite surfaces, suggesting that the removal of AT from solution was via sorption instead of precipitation. In addition, the (001) peak of kaolinite did not change at all (Figure 8), indicating that AT sorption sites were on the external surface or edges, instead of interlayer. Similar results were observed in the XRD patterns of physical mixture of AT and hydrophilic swellable polymers, indicating that AT was completely dispersed in the solid substrate [32].

3.8. Discussion on AT Adsorption Mechanism. Although several studies were reported on the uptake and adsorption of AT by AC, sediments, and some clay minerals, mixed results often lead to contradicting results. Cation exchange was attributed to the dominating role for the retardation of AT in different sediments $[2,3]$. However, similar AT adsorption capacities on both kaolinite and bentonite were obtained, even though the CEC of kaolinite was much lower than that of

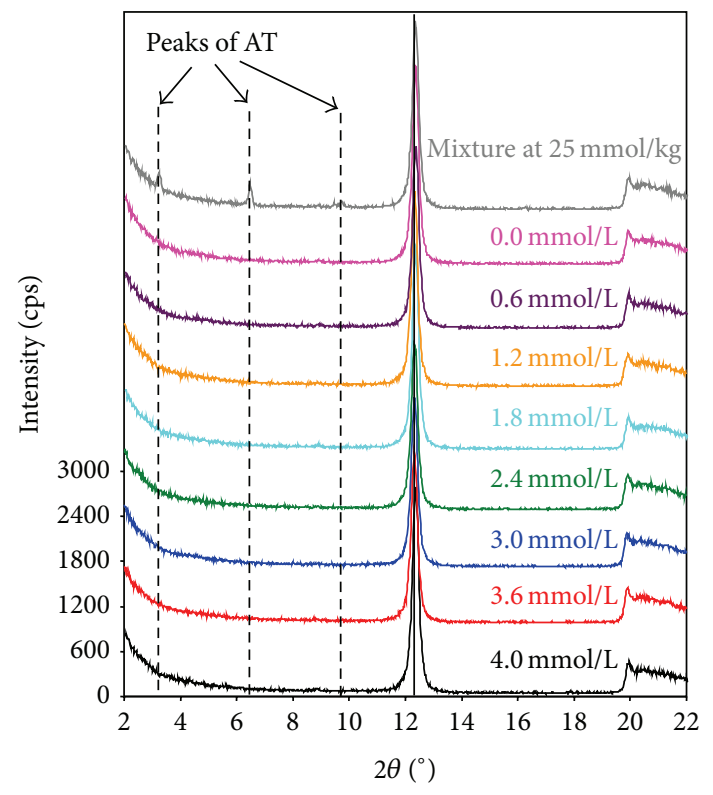

FIGURE 8: X-ray diffraction patterns of kaolinite adsorbed with different amounts of AT. The values are initial AT concentrations.

bentonite, which seemed that the uptake of TA on these minerals was not strongly related to the cation exchange processes [8]. Moreover, the contribution of electrostatic interactions to overall adsorption of AT on sediments and sludge was thought rather small, as significant shifting of AT from solution into the sediment was not observed [1]. In one study, adsorption onto organic carbon was considered as the relevant adsorption process for AT uptake onto sediments [1]. On the contrary, the influence of organic matter on the adsorption of AT and metoprolol on aquifer sediments was much less important [33].

In this study, the AT adsorption capacity on kaolinite was $40 \mathrm{mmol} / \mathrm{kg}$, while the CEC of the kaolinite was $37 \mathrm{mmol}_{\mathrm{c}} / \mathrm{kg}$ [17]. Thus, to the first degree, the AT adsorption capacities matched the CEC values of these minerals well. In addition, the reduced AT uptake at low $\mathrm{pH}$ and high ionic strength conditions also suggested that cation exchange mechanism or electrostatic interactions played important roles on AT uptake by kaolinite. However, IC results showed nondetectable $\mathrm{Na}^{+}, \mathrm{K}^{+}, \mathrm{Mg}^{2+}$, and $\mathrm{Ca}^{2+}$ in the supernatants, suggesting no release of exchangeable cations after AT uptake (data not shown). In contrast, stoichiometric release of exchangeable cations was observed after ciprofloxacin adsorption on the same kaolinite [28].

A newly proposed cation exchange model that defined the adsorption of organic cations to soil as a summed contribution of adsorption to organic matter (OM) and adsorption to phyllosilicate clay minerals showed good agreement between the observed and predicted $K_{d}$ values within a factor of 3 [34]. The equation used was

$$
\begin{aligned}
K_{d} & =K_{\mathrm{CEC}, \mathrm{CLAYS}} \mathrm{CEC}_{\mathrm{CLAY}}+f_{\mathrm{OC}} D_{\mathrm{OC}, \mathrm{IE}} \\
& =K_{\mathrm{CEC}, \mathrm{CLAYS}}\left(\mathrm{CEC}_{\mathrm{SOIL}}-3.4 f_{\mathrm{OC}}\right)+f_{\mathrm{OC}} D_{\mathrm{OC}, \mathrm{IE}},
\end{aligned}
$$




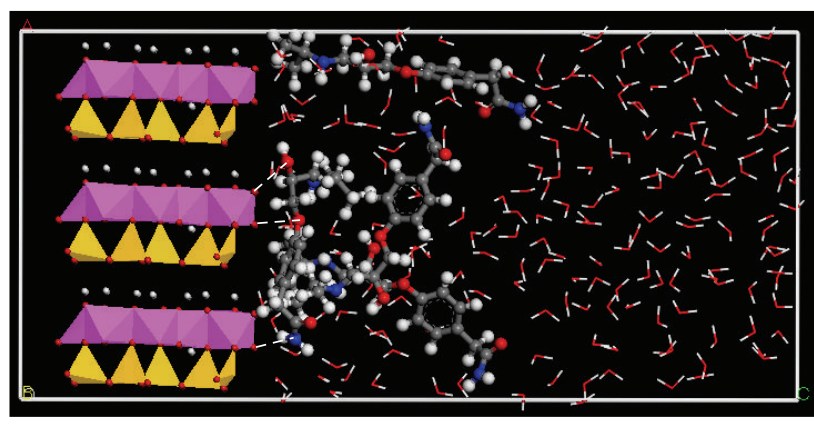

(a)

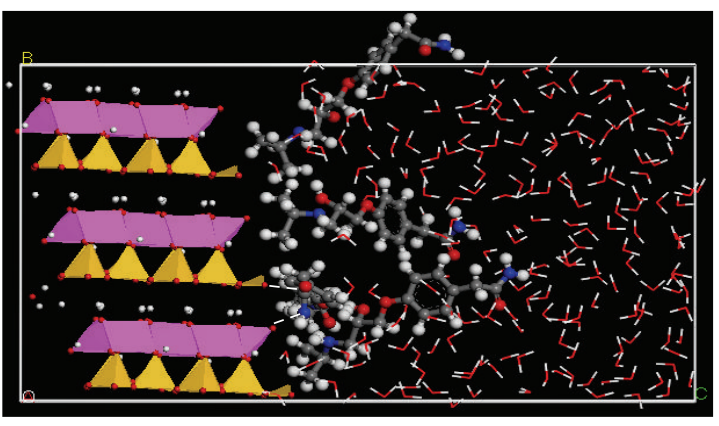

(b)

FIGURE 9: Interactions between AT and kaolinite on (100) (a) and (010) (b). Dashed lines indicate hydrogen bonding.

where $f_{\mathrm{OC}}$ was the faction of organic carbon and $D_{\mathrm{OC}, \mathrm{IE}}$ and $K_{\text {CEC,CLAY }}$ were the ion-exchange-based adsorption coefficients for NOM and clay. However, due to the fact that AT adsorption on kaolinite did not follow the linear adsorption isotherm and the $f_{\mathrm{OC}}$ value for the pure kaolinite was essentially zero, the $K_{d}$ value in this study varied with the equilibrium AT concentration. Thus, for pure clay minerals, this equation may not be applicable.

One important piece of information from the FTIR study was the breakup of the bands at 1412 and $1240 \mathrm{~cm}^{-1}$, each into two. These bands were attributed to $\mathrm{NH}$ bending vibrations [29] and alkyl aryl ether linkage [4]. Thus, it is more likely that the adsorption of AT on low charge kaolinite was via electrostatic interaction between the amine group of AT and the negatively charged mineral surface and/or hydrogen bonding between the hydroxyl group of the kaolinite and the alkyl aryl ether linkage, as confirmed by molecular simulation of AT adsorption on the (100) and (010) surfaces of kaolinite (Figure 9).

\section{Conclusions}

Strong interactions between AT and kaolinite were revealed in this study. The AT adsorption capacity on kaolinite was close to its cation exchange capacity value and the AT adsorption was almost instantaneous, suggesting surface adsorption instead of intercalation, as confirmed by X-ray diffraction analyses. Both solution $\mathrm{pH}$ and ionic strength had significant effect on AT adsorption on kaolinite. An increase in ionic strength of the solution drastically reduced AT adsorption and at solution $\mathrm{pH}$ below 5 or above $10 \mathrm{AT}$ adsorption was significantly reduced, too. The FTIR results showed band shifting and disappearance for $\mathrm{NH}$ bending vibration and benzene ring skeletal vibration at 3360 and $1515 \mathrm{~cm}^{-1}$ and band splitting at 1412 and $1240 \mathrm{~cm}^{-1}$ attributed to $\mathrm{C}-\mathrm{N}$ valence vibration coupled with $\mathrm{NH}$ bending vibrations and alkyl aryl ether linkage, suggesting the participation of $\mathrm{NH}$, $-\mathrm{O}-$, and benzene ring for AT adsorption on kaolinite. Molecular simulation results confirmed the FTIR observations.

\section{Conflict of Interests}

The authors declare that there is no conflict of interests regarding the publication of this paper.

\section{References}

[1] A. Küster, A. C. Alder, B. I. Escher et al., "Environmental risk assessment of human pharmaceuticals in the European union: a case study with the $\beta$-blocker atenolol," Integrated Environmental Assessment and Management, vol. 6, supplement 1, pp. 514-523, 2010.

[2] M. Schaffer, N. Boxberger, H. Börnick, T. Licha, and E. Worch, "Sorption influenced transport of ionizable pharmaceuticals onto a natural sandy aquifer sediment at different $\mathrm{pH}$," Chemosphere, vol. 87, no. 5, pp. 513-520, 2012.

[3] H. Yamamoto, Y. Nakamura, S. Moriguchi et al., "Persistence and partitioning of eight selected pharmaceuticals in the aquatic environment: laboratory photolysis, biodegradation, and sorption experiments," Water Research, vol. 43, no. 2, pp. 351-362, 2009.

[4] Seema and M. Datta, "In vitro sustained delivery of atenolol, an antihypertensive drug using naturally occurring clay mineral montmorillonite as a carrier," European Chemical Bulletin, vol. 2, no. 11, pp. 942-951, 2013.

[5] A. de Sousa, K. C. de Souza, P. M. D. S. Leite, R. G. de Sousa, and E. M. B. de Sousa, "A dual-functional [SBA- $15 / \mathrm{Fe}_{3} \mathrm{O}_{4} / \mathrm{P}(N-$ iPAAm)] hybrid system as a potential nanoplatform for biomedical application," Journal of Nanomaterials, vol. 2014, Article ID 293624, 10 pages, 2014.

[6] R. W. Novickis, M. V. S. Martins, L. F. de Miranda, R. R. Ribeiro, L. Silva, and A. H. Munhoz Jr., "Development of nanosystems to release atenolol," Advances in Science and Technology, vol. 86, pp. 102-107, 2013.

[7] Y. Deng, F. Wu, B. Liu, X. Hu, and C. Sun, "Sorptive removal of $\beta$-blocker propranolol from aqueous solution by modified attapulgite: effect factors and sorption mechanisms," Chemical Engineering Journal, vol. 174, no. 2-3, pp. 571-578, 2011.

[8] V. Rakić, N. Rajić, A. Daković, and A. Auroux, “The adsorption of salicylic acid, acetylsalicylic acid and atenolol from aqueous solutions onto natural zeolites and clays: clinoptilolite, bentonite and kaolin," Microporous and Mesoporous Materials, vol. 166, pp. 185-194, 2013.

[9] D. K. Rao, T. Damodharam, J. S. Yadav, and P. S. Babu, "Removal of atenolol ( $\beta$-blocker) from aqueous phase by sorption onto activated charcoal," International Journal of Pharmaceutical and Chemical Sciences, vol. 2, pp. 355-368, 2013.

[10] J. L. S. Sancho, A. R. Rodríguez, S. Á. Torrellas, and J. G. Rodríguez, "Removal of an emerging pharmaceutical compound by adsorption in fixed bed column," Desalination and Water Treatment, vol. 45, no. 1-3, pp. 305-314, 2012. 
[11] J. L. Sotelo, G. Ovejero, A. Rodríguez, S. Álvarez, and J. García, "Removal of atenolol and isoproturon in aqueous solutions by adsorption in a fixed-bed column," Industrial \& Engineering Chemistry Research, vol. 51, no. 13, pp. 5045-5055, 2012.

[12] M. Ramil, T. El Aref, G. Fink, M. Scheurer, and T. A. Ternes, "Fate of beta blockers in aquatic-sediment systems: sorption and biotransformation," Environmental Science \& Technology, vol. 44, no. 3, pp. 962-970, 2010.

[13] M. Barbieri, T. Licha, K. Nödler, J. Carrera, C. Ayora, and X. Sanchez-Vila, "Fate of $\beta$-blockers in aquifer material under nitrate reducing conditions: batch experiments," Chemosphere, vol. 89, no. 11, pp. 1272-1277, 2012.

[14] W. Song, W. J. Cooper, S. P. Mezyk, J. Greaves, and B. M. Peake, "Free radical destruction of $\beta$-blockers in aqueous solution," Environmental Science and Technology, vol. 42, no. 4, pp. 12561261, 2008.

[15] E. Hapeshi, A. Achilleos, M. I. Vasquez et al., "Drugs degrading photocatalytically: kinetics and mechanisms of ofloxacin and atenolol removal on titania suspensions," Water Research, vol. 44, no. 6, pp. 1737-1746, 2010.

[16] A. Jelić, M. Gros, M. Petrović, A. Ginebreda, and D. Barceló, "Occurrence and elimination of pharmaceuticals during conventional wastewater treatment," in Emerging and Priority Pollutants in Rivers, The Handbook of Environmental Chemistry, pp. 1-23, Springer, Berlin, Germany, 2011.

[17] D. Borden and R. F. Giese, "Baseline studies of the clay minerals society source clays: cation exchange capacity measurements by the ammonia-electrode method," Clays and Clay Minerals, vol. 49, no. 5, pp. 444-445, 2001.

[18] A. U. Dogan, M. Dogan, M. Onal, Y. Sarikaya, A. Aburub, and D. E. Wurster, "Baseline studies of the clay minerals society source clays: specific surface area by the Brunauer Emmett Teller (BET) method," Clays and Clay Minerals, vol. 54, no. 1, pp. 62-66, 2006.

[19] D. T. Manallack, "The $\mathrm{p} K_{a}$ distribution of drugs: application to drug discovery," Perspectives in Medicinal Chemistry, vol. 1, pp. 25-38, 2007.

[20] K. M. Al Azzam, B. Saad, and H. Y. Aboul-Enein, "Simultaneous determination of atenolol and amiloride in pharmaceutical preparations by capillary zone electrophoresis with capacitively coupled contactless conductivity detection," Biomedical Chromatography, vol. 24, no. 9, pp. 948-953, 2010.

[21] J. L. R. Silveira, S. R. Dib, and A. M. Faria, "New support for high-performance liquid chromatography based on silica coated with alumina particles," Analytical Sciences, vol. 30, no. 2, pp. 285-291, 2014.

[22] S. N. A. Vinnakota, R. Deveswaran, S. Bharath, B. V. Basavaraj, and V. Madhavan, "Spectrophotometric estimation and validation of atenolol in tablets by hydrotropic solubilisation," Current Pharma Research, vol. 2, no. 1, pp. 385-388, 2011.

[23] A. Avdeef, C. M. Berger, and C. Brownell, "pH-metric solubility. 2: correlation between the acid-base titration and the saturation shake-flask solubility-pH methods," Pharmaceutical Research, vol. 17, no. 1, pp. 85-89, 2000.

[24] N. T. Hansen, I. Kouskoumvekaki, F. S. Jørgensen, S. Brunak, and S. Ó. Jónsdóttir, "Prediction of pH-dependent aqueous solubility of druglike molecules," Journal of Chemical Information and Modeling, vol. 46, no. 6, pp. 2601-2609, 2006.

[25] A. Weich, D. C. De Oliveira, J. De Melo, K. Goebel, and C. M. B. Rolim, "Validation of UV spectrophotometric and HPLC methods for quantitative determination of atenolol in pharmaceutical preparations," Latin American Journal of Pharmacy, vol. 26, no. 5, pp. 765-770, 2007.
[26] K. S. Sable, N. N. Ghadge, M. B. Hole, and M. V. Gadhave, "Development of a UV-spectrophotometric method for the simultaneous determination of nifedipine and atenolol in combined dosage form," International Journal of Institutional Pharmacy and Life Sciences, vol. 2, no. 2, pp. 380-389, 2012.

[27] Y. S. Ho, "Review of second-order models for adsorption systems," Journal of Hazardous Materials, vol. 136, no. 3, pp. 681689, 2006.

[28] Z. Li, H. Hong, L. Liao et al., "A mechanistic study of ciprofloxacin removal by kaolinite," Colloids and Surfaces B: Biointerfaces, vol. 88, no. 1, pp. 339-344, 2011.

[29] C. V. Nikolić, L. J. Nikolić, M. Stanković, A. Kapor, M. Popsavin, and D. Cvetković, "A molecular inclusion complex of atenolol with 2 -hydroxypropyl- $\beta$-cyclodextrin; the production and characterization thereof," Journal of the Serbian Chemical Society, vol. 72, no. 8-9, pp. 737-746, 2007.

[30] E. S. El-Leithy, M. Nasr, and R. A. El-Moneum, "Development and characterization of solid lipid dispersion as delivery system for hydrophilic antihypertensive drug atenolol," International Journal of Drug Delivery, vol. 4, no. 2, pp. 219-228, 2012.

[31] R. A. E. de Castro, J. Canotilho, R. M. Barbosa et al., "Conformational isomorphism of organic crystals: racemic and homochiral atenolol," Crystal Growth and Design, vol. 7, no. 3, pp. 496-500, 2007.

[32] S. Kumar, M. Das, K. S. Gupta, R. Kumar, A. Chongdar, and L. K. Ghosh, "Design, development, optimization and evaluation of gastro-retentive floating tablets of atenolol," Der Pharmacia Lettre, vol. 5, no. 3, pp. 436-456, 2013.

[33] A. Niedbala, M. Schaffer, T. Licha et al., "Influence of competing inorganic cations on the ion exchange equilibrium of the monovalent organic cation metoprolol on natural sediment," Chemosphere, vol. 90, no. 6, pp. 1945-1951, 2013.

[34] S. T. J. Droge and K. U. Goss, "Development and evaluation of a new sorption model for organic cations in soil: contributions from organic matter and clay minerals," Environmental Science \& Technology, vol. 47, no. 24, pp. 14233-14241, 2013. 

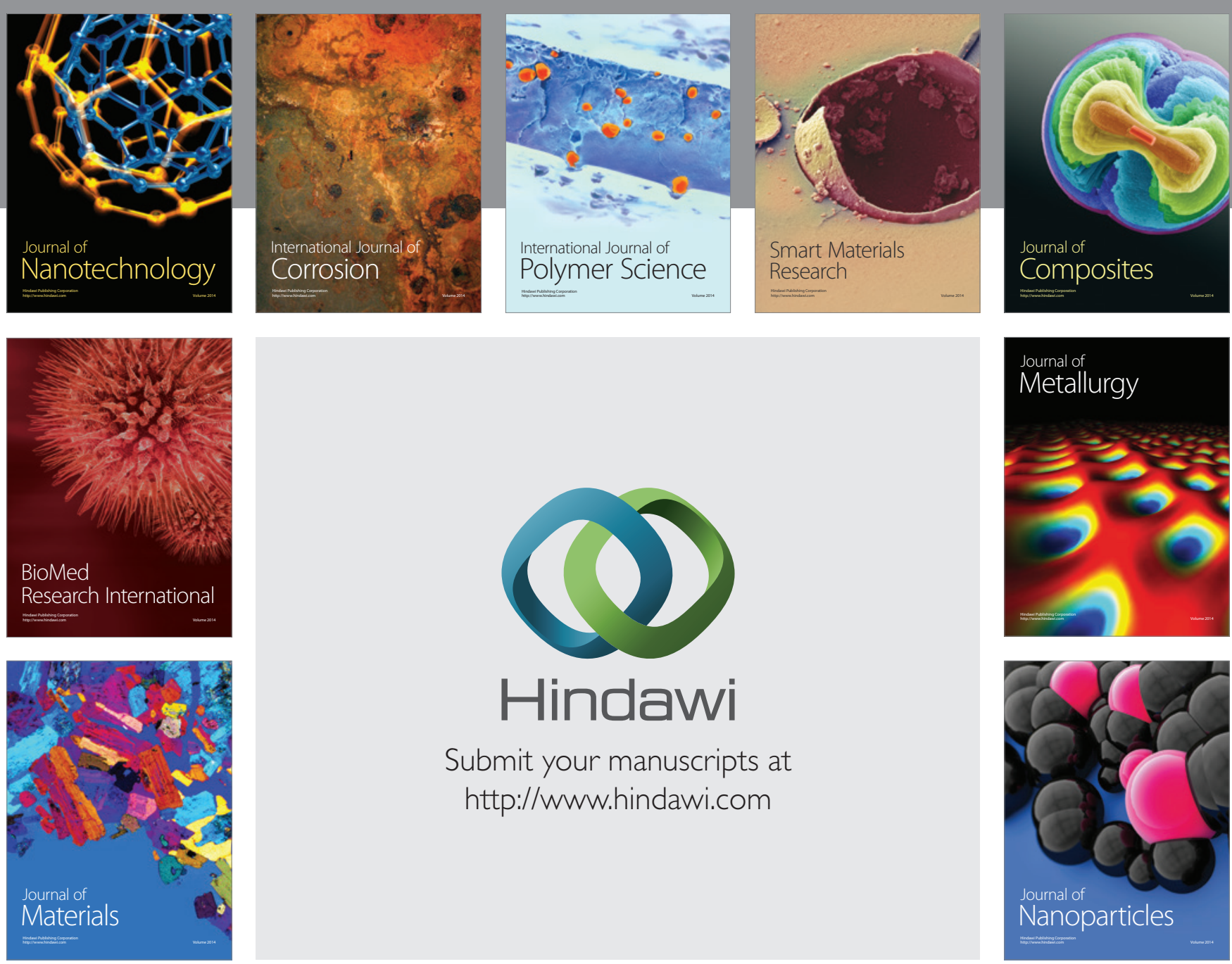

Submit your manuscripts at http://www.hindawi.com
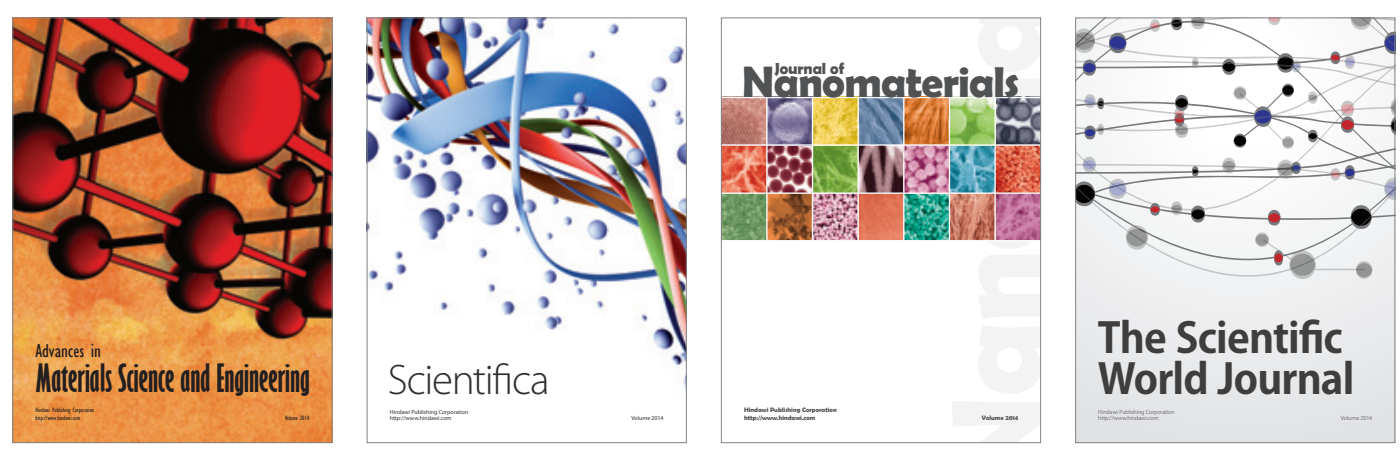

\section{The Scientific World Journal}
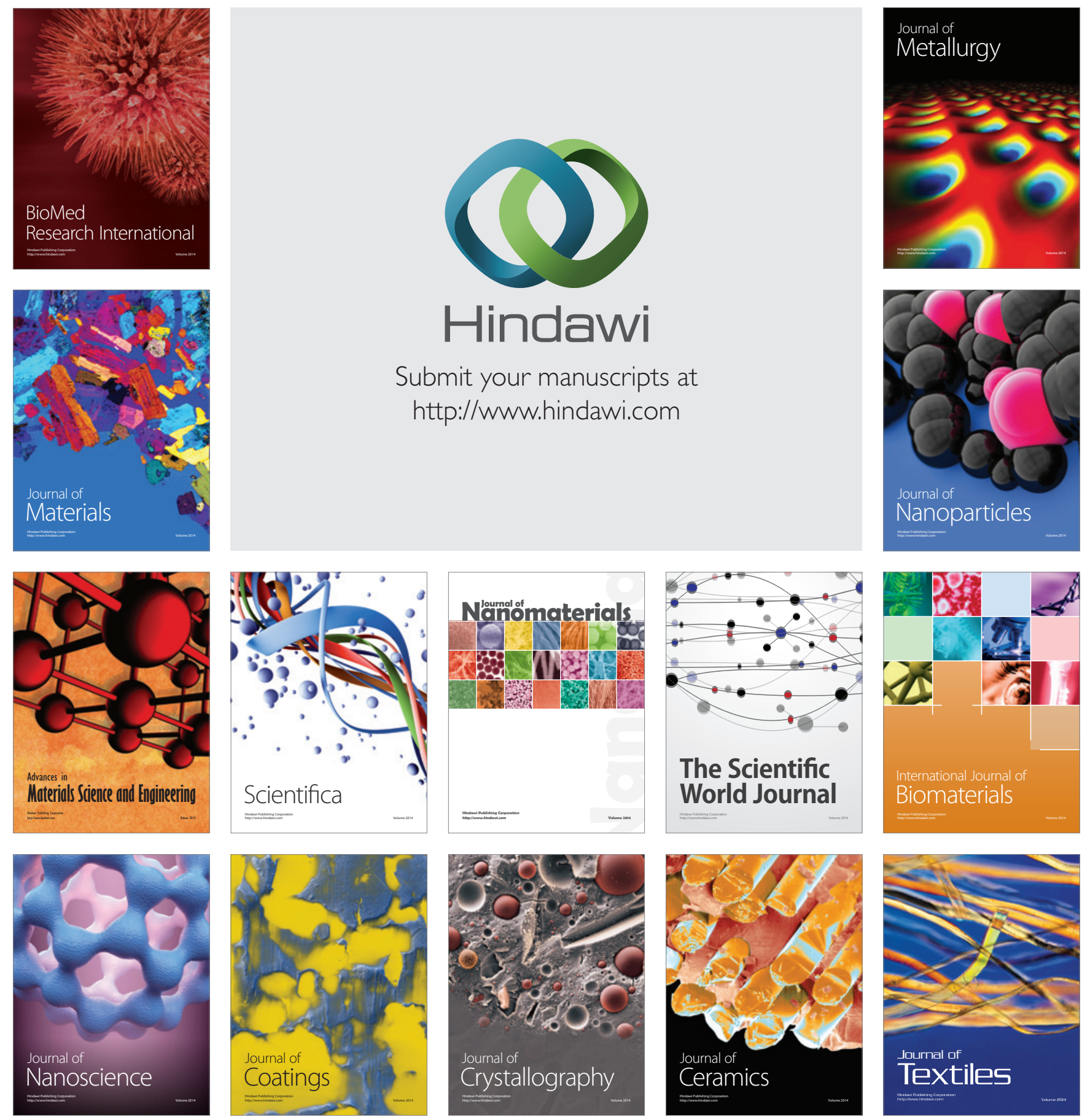